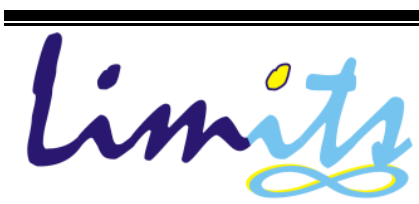

Journal of Mathematics and Its Applications

E-ISSN: 2579-8936

P-ISSN: $1829-605 X$

Vol. 16, No. 1, Agustus 2019, 63-71

\title{
Pengaruh Pasif Kontrol terhadap Koefisien Hambat
}

\author{
Chairul Imron $^{1} *$, Bas uki Widodo ${ }^{2}$, Triyogi Yuwono ${ }^{3}$ \\ ${ }^{1,2}$ Departemen Matematika ITS Surabaya Indonesia \\ ${ }^{3}$ Departemen Teknik Mesin ITS Surabaya Indonesia \\ e-mail: 1imron-its@ matematika.its.ac.id, 22b_widodo@matematika.its.ac.id, ${ }^{3}$ triyogi@me.its.ac.id
}

\begin{abstract}
Abstrak
Salah satu cara untuk mengurangi koefisien hambat adalah dengan menambahkan obyek kecil yang dinamakan pasif kontrol. Tiga pasif kontrol, terdiri satu pasif kontrol berbentuk silinder tipe-I diletakkan di depan dan dua silinder sirkular diletakkan di belakang silinder sirkular utama. Diameter silinder sirkular utama adalah $\mathrm{D}$ dan tiga silinder pasif kontrol berdiameter $d=D / 8$. Rasio jarak antara pasif kontrol di depan dengan silinder sirkular utama adalah $S / D=[0.6,3.0]$ dan dua pasif kontrol di belakang silinder sirkular yaitu $T / D=[0.6,2.1]$ dan besar sudut $\alpha=15^{\circ}, 30^{\circ}, 45^{\circ}$ dan $60^{\circ}$. Bilangan Reynolds yang digunakan adalah $\operatorname{Re}=1000$. Konfigurasi yang tepat untuk menurunkan koefisien hambat terjadi ketika rasio jarak $S / D=1.8$ dan $T / D=1.5$ dengan $\alpha=30^{\circ}$. Koefisien hambat yang diterima silinder sirkular dapat berkurang hingga $42.98 \%$.
\end{abstract}

Kata Kunci: Pasif Kontrol, Silinder Sirkular, Simulasi Numerik, Persamaan Navier-Stokes

\begin{abstract}
One way to reduce the drag coefficient is to add a small object called passive control. Three passive controls, consisting of a type-I cylindrical are placed in front and two circular cylinders are placed behind the main circular cylinder. The diameter of the main circular cylinder is $D$ and the diameter of the three passive controls are $d=D / 8$. The distance ratio between the passive control in front of the main circular cylinder is $S / D=[0.6,3.0]$ and two passive controls behind the circular cylinder, $T / D=[0.6,2.1]$ with the angle $\alpha=15^{\circ}, 30^{\circ}, 45^{\circ}$ and $60^{\circ}$. The Reynolds number used is Re $=1000$. The best configuration to reduce the drag coefficient occurs when the distance ratio $S / D=1.8$ and $T / D=1.5$ with $\alpha=30^{\circ}$. The drag coefficient received by the circular cylinder can be reduced to $42.98 \%$.
\end{abstract}

Keywords: Passive Control, Circular Cylinder, Numerical Simulation, Navier-Stokes Equation

\section{Pendahuluan}

Penelitian tentang fenomena aliran fluida melintasi permukaan luar suatu benda telah berubah dengan cepat setelah konsep lapisan batas ditemukan. Konsep lapisan batas berhasil mengungkapkan beberapa jawaban tentang pengaruh tegangan geser terhadap karakteristik aliran fluida di sekitar objek. Penelitian aliran fluida melintasi objek tunggal berbentuk silinder sirkular telah banyak dilakukan [1]. Penelitian lainnya antara lain modifikasi objek silinder sirkular dalam bentuk silinder tipe-D atau tipe-I [2,3], aliran fluida melalui lebih dari satu silinder dengan ukuran yang sama atau berbeda konfigurasi dalam posisi side-by-side atau tandem $[3,4,5,6,7]$. 
Aliran fluida yang melintasi objek menimbulkan gaya hambat yang dapat menyebabkan kekuatan objek berkurang. Untuk itu, koefisien hambat yang diterima objek perlu dikurangi dengan cara meletakkan pasif kontrol di sekitar objek. Pasif kontrol berbentuk silinder sirkular kecil diletakkan di sekitar silinder sirkular utama. Hasilnya, penambahan pasif kontrol tersebut dapat mengurangi koefisien hambat dibandingkan dengan tanpa pasif kontrol, dengan diameter silinder dan bilangan Reynolds yang sama [4]. Pada beberapa macam bilangan Reynolds yang berbeda yaitu $1.5 \times 10^{4}-6.2 \times 10^{4}$. Hasil penelitian menunjukkan bahwa variasi bilangan Reynolds $R e>3 \times 10^{4}$ menyebabkan koefisien tekanan minimum [8]. Penelitian lainnya, dengan modifikasi pasif kontrol menjadi silinder tipe-D, koefisien hambat mampu berkurang hingga 7\% dibandingkan tanpa pasif control [6]. Modifikasi pasif kontrol menjadi silinder tipe-I dengan meletakkan pada jarak tertentu dapat mengurangi koefisien hambat yang diterima silinder sirkular utama paling optimal [7]. Pada paper ini, aliran fluida melalui silinder sirkular dan tiga pasif kontrol pada bilangan Reynolds 1000. Penambahan pasif kontrol bertujuan untuk mengurangi koefisien hambat lebih optimal.

\section{Metode Penelitian}

Berikut ini diberikan beberapa tahapan dalam pembuatan paper ini yaitu sebagai berikut

\subsection{Persamaan Matematika}

Persamaan matematika untuk aliran fluida berdasarkan persamaan Navier-Stokes nondimensional untuk fluida steady dan incompressible.

$$
\begin{gathered}
\frac{\partial \vec{u}}{\partial t}+(\nabla \vec{u}) \vec{u}+\nabla \mathrm{p}=\frac{1}{\operatorname{Re}} \nabla^{2} \vec{u} \\
\nabla \overrightarrow{\mathrm{u}}=0
\end{gathered}
$$

Dimana $\vec{u}$ adalah komponen vektor kecepatan aliran pada arah sumbu- $x$ dan sumbu- $y, p$ adalah tekanan fluida yang diterima permukaan dan $R e$ adalah bilangan Reynolds.

\subsection{Penyelesaian Numerik}

Persamaan Navier-Stokes diselesaikan dengan menerapkan algoritma SIMPLE dan didiskritkan menggunakan skema beda hingga [14]. Alur algoritma SIMPLE dimulai dengan menyelesaikan persamaan adveksi-diffusi untuk memperoleh kecepatan sementara pada sumbu$x$ dan sumbu- $y$.

$$
\frac{\vec{u}_{i, j}^{\prime}-\vec{u}_{i, j}^{n}}{\Delta t}=-\left(u \frac{\partial \vec{u}}{\partial x}+v \frac{\partial \vec{u}}{\partial y}\right)+\frac{1}{R e}\left(\frac{\partial^{2} \vec{u}}{\partial x^{2}}+\frac{\partial^{2} \vec{u}}{\partial y^{2}}\right)
$$

Persamaan (3) didiskritkan dengan skema beda hingga sebagai berikut: 


$$
\begin{array}{crl}
\frac{\partial \vec{u}}{\partial x}=\frac{2 \vec{u}_{i+1, j}^{n}+3 \vec{u}_{i, j}^{n}-6 \vec{u}_{i-1, j}^{n}+\vec{u}_{i-2, j}^{n}}{6 \Delta x} & \frac{\partial \vec{u}}{\partial y}=\frac{2 \vec{u}_{i, j+1}^{n}+3 \vec{u}_{i, j}^{n}-6 \vec{u}_{i, j-1}^{n}+\vec{u}_{i, j-2}^{n}}{6 \Delta y} \\
\frac{\partial \vec{u}}{\partial x}=\frac{\vec{u}_{i+1, j}^{n}-2 \vec{u}_{i, j}^{n}+\vec{u}_{i-1, j}^{n}}{(\Delta x)^{2}} & \frac{\partial \vec{u}}{\partial y}=\frac{\vec{u}_{i+1, j}^{n}-2 \vec{u}_{i, j}^{n}+\vec{u}_{i-1, j}^{n}}{(\Delta y)^{2}}
\end{array}
$$

Langkah selanjutnya yaitu menyelesaikan persamaan poisson untuk memperoleh tekanan berdasarkan kecepatan yang diperoleh sebelumnya.

$$
\frac{\nabla \vec{u}^{\prime}}{\Delta t}=-\nabla^{2} p
$$

$\nabla^{2}$ adalah operator laplace. Persamaan (4) didiskritkan dengan menerapkan skema sebagai berikut

$$
\nabla^{2} p=\frac{p_{i+1, j}+p_{i-1, j}+p_{i, j+1}+p_{i, j-1}-4 p_{i, j}}{(\Delta x)^{2}}
$$

Langkah terakhir yaitu melakukan koreksi komponen kecepatan dengan persamaan sebagai berikut

$$
\frac{\partial \vec{u}}{\partial t}=-\nabla p
$$

\subsection{Domain dan Syarat Batas}

Simulasi aliran fluida diterapkan pada area domain ukuran 20Dx10D, dengan D adalah diameter silinder sirkular. Pada domain ukuran tersebut dibagi menjadi 800x400 grid seragam. Silinder sirkular diletakkan pada posisi 4D, 5D, pasif kontrol diletakkan di depan silinder dan di belakang silinder pada jarak yang berbeda-beda. Skema tersebut dapat dilihat di hasil dan pembahasan. Dalam simulasi ini, diasumsikan aliran fluida mengalir dengan kecepatan yang sama di daerah bebas, dan fluida yang berada di titik stagnasi permukaan silinder sirkular memiliki kecepatan nol. Dengan asumsi-asumsi ini, kecepatan aliran fluida yang berada di sekitar permukaan silinder sirkular akan melambat.

\subsection{Validasi}

Hasil penyelesaian numerik divalidasi dengan membandingkan hasil koefisien hambat yang diterima silinder sirkular tunggal tanpa pasif kontrol dengan hasil penelitian lainnya pada bilangan Reynolds 100. Skema aliran fluida yang melalui silinder sirkular tanpa pasif kontrol dapat dilihat pada Gambar 1. 

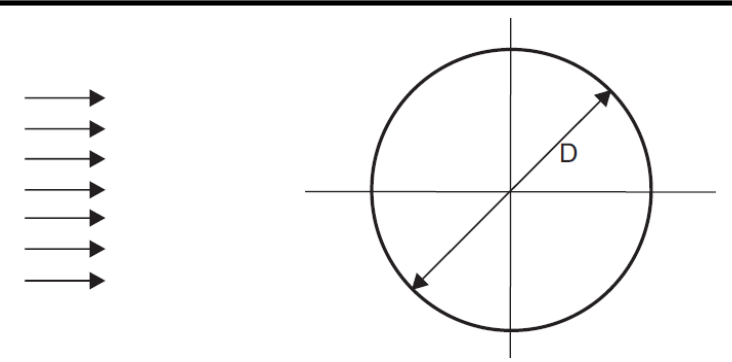

Gambar 1 Skema Aliran Fluida Melintasi Silinder Sirkular Tunggal

Tabel 1. Perbandingan Koefisien Hambat Pada Bilangan Reynolds 100

\begin{tabular}{|l|c|c|}
\hline Peneliti & Koefisien Hambat (Re=100) & Koefisien Hambat (Re=1000) \\
\hline Penelitian saat ini & 1.358 & 1.21 \\
\hline Lima, dkk.[11] & 1.39 & - \\
\hline Zulhidayat, dkk.[12] & 1.4 & - \\
\hline Sintu, dkk.[13] & 1.431 & - \\
\hline
\end{tabular}

Berdasarkan Tabel 1, error relative hasil koefisien hambat yang diperoleh penelitian saat ini tidak melebihi 5.2\%. maka, penyelesian numerik persamaan Navier-Stokes dengan algoritma SIMPLE dan metode beda hingga dapat digunakan untuk menghitung koefisien hambat yang diterima silinder sirkular dengan pasif kontrol.

\section{Hasil dan Pembahasan}

Tata letak pasif kontrol yang tepat dapat mempengaruhi penurunan koefisien hambat yang optimal. Pasif kontrol tunggal yang diletakkan di depan silinder pada jarak yang bervariasi ditunjukkan pada Gambar 2. Bentuk pasif kontrol tersebut adalah modifikasi dari silinder sirkular kecil berdiameter $d$ yang dipotong bagian depan dan bagian belakang dengan sudut potong $53^{\circ}$. Sehingga, terbentuk silinder tipe-I, dimana $d=0.125 D$.

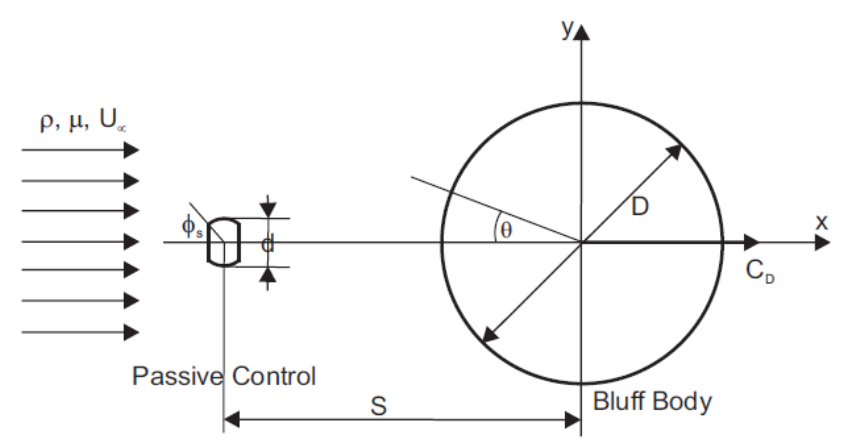

Gambar 2 Skema Aliran Fluida Melintasi Silinder Sirkular dan Pasif Kontrol Tunggal

Variasi rasio jarak silinder sirkular dan pasif kontrol adalah $S / D=[0.6,3.0]$ dengan increment 0.6. Koefisien hambat yang diterima silinder sirkular dengan pasif kontrol tunggal ditunjukkan pada Tabel 2. Posisi pasif kontrol yang lebih dekat dengan silinder sirkular belum 
optimal untuk menurunkan koefisien hambat. Demikian juga pasif kontrol yang terletak lebih jauh dari silinder sirkular. Posisi yang paling optimal untuk menurunkan koefisien hambat yaitu pada rasio jarak 2.4, koefisien hambat dapat diturunkan hingga $26.09 \%$.

Tabel 2. Koefisien Hambat Dengan Variasi S/D Menggunakan Pasif Kontrol Tunggal

\begin{tabular}{|c|c|c|c|c|c|}
\hline S/D & $\mathbf{0 . 6}$ & $\mathbf{1 . 2}$ & $\mathbf{1 . 8}$ & $\mathbf{2 . 4}$ & $\mathbf{3 . 0}$ \\
\hline $\mathrm{Cd}$ & 1.114 & 0.946 & 0.896 & 0.894 & 0.911 \\
\hline$\%$ & $7.864 \%$ & $21.814 \%$ & $25.92 \%$ & $26.09 \%$ & $24.698 \%$ \\
\hline
\end{tabular}

Penelitian dilanjutkan dengan menambahkan satu pasif kontrol berbentuk silinder sirkular kecil yang diletakkan di belakang silinder sirkular utama. Skema silinder sirkular dan dua pasif kontrol ditunjukkan pada Gambar 3. Rasio jarak antara pasif kontrol pertama dengan silinder sirkular yaitu $S / D=[0.6,3.0]$ dengan increment 0.6. sedangkan, rasio jarak antara pasif kontrol kedua dengan silinder sirkular yaitu $T / D=[0.6,2.1]$ dengan increment 0.3 .

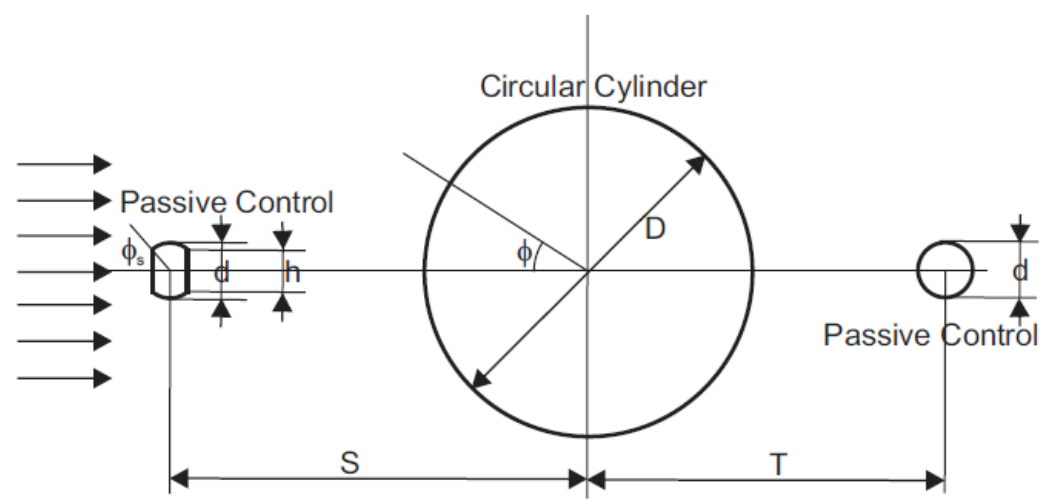

Gambar 3 Skema Aliran Fluida Melintasi Silinder Sirkular dan Dua Pasif Kontrol

Koefisien hambat yang diterima silinder sirkular dan dua pasif kontrol ditunjukkan pada Tabel 3. Penurunan koefisien hambat yang paling besar yaitu saat pasif kontrol pertama diletakkan di depan silinder sirkular pada jarak $\mathrm{S} / \mathrm{D}=2.4$ dan pasif kontrol kedua di belakang silinder sirkular pada jarak $\mathrm{T} / \mathrm{D}=2.1$. Pada posisi tersebut, koefisien hambat dapat berkurang hingga $31.20 \%$.

Penelitian yang hampir sama yaitu silinder sirkular dengan dua pasif kontrol, dimana pasif kontrol di belakang silinder berbentuk silinder tipe I pada posisi horizontal. Pada rasio jarak S/D dan T/D yang sama, koefisien hambat yang diterima silinder sirkular dapat berkurang hingga $30.992 \%$ [9]. Bentuk pasif kontrol lainnya yang diletakkan di belakang silinder yaitu bentuk elips. Pada posisi yang sama, koefisien hambat yang diterima silinder sirkular dapat berkurang 
hingga 31.90\% [10]. Berdasarkan tiga bentuk pasif kontrol yang diletakkan di belakang silinder sirkular, pasif kontrol bentuk elips dapat menurunkan koefisien hambat secara optimal.

Tabel 3. Koefisien Hambat Dengan Variasi T/D dan S/D Menggunakan Dua Pasif Kontrol

\begin{tabular}{|c|c|c|c|c|c|}
\hline $\mathbf{T} / \mathbf{D}, \mathbf{S} / \mathbf{D}$ & $\mathbf{0 . 6}$ & $\mathbf{1 . 2}$ & $\mathbf{1 . 8}$ & $\mathbf{2 . 4}$ & $\mathbf{3 . 0}$ \\
\hline 0.6 & 1.092 & 0.925 & 0.876 & 0.874 & 0.891 \\
\hline 0.9 & 1.066 & 0.901 & 0.852 & 0.851 & 0.868 \\
\hline 1.2 & 1.067 & 0.902 & 0.853 & 0.852 & 0.869 \\
\hline 1.5 & 1.055 & 0.891 & 0.843 & 0.842 & 0.859 \\
\hline 1.8 & 1.043 & 0.882 & 0.835 & 0.834 & 0.851 \\
\hline 2.1 & 1.038 & 0.878 & 0.833 & 0.832 & 0.849 \\
\hline
\end{tabular}

Silinder sirkular dengan tiga pasif kontrol, dimana satu pasif kontrol diletakkan di depan silinder sirkular dan dua pasif kontrol diletakkan di belakang silinder sirkular. Skema silinder sirkular dan tiga pasif kontrol ditunjukkan pada Gambar 4.

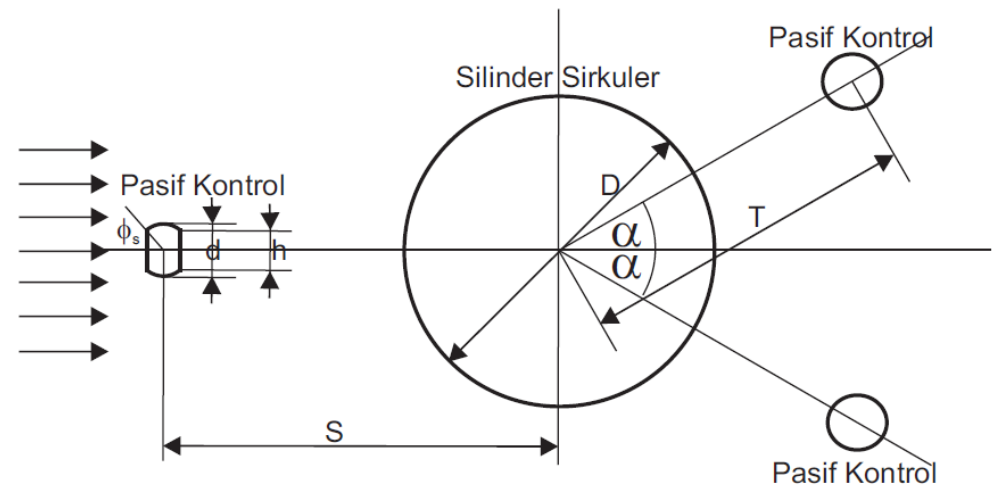

Gambar 4 Skema Aliran Fluida Melintasi Silinder Sirkular dan Tiga Pasif Kontrol

Rasio jarak antara pasif kontrol dan silinder sirkular masih sama dengan skema silinder sirkular dengan dua pasif kontrol. Pada skema tiga pasif kontrol, besar sudut antara dua pasif kontrol di belakang silinder sirkular adalah $2 \alpha$. Uji coba dilakukan dengan $\alpha$ yang bervariasi yaitu $\alpha=\left[15^{\circ}, 90^{\circ}\right]$.

Tabel 4. Koefisien Hambat Pada S/D=1.2, Variasi T/D dan $\alpha$ Dengan Tiga Pasif Kontrol

\begin{tabular}{|c|c|c|c|}
\hline${ }^{\circ},(\mathbf{S} / \mathbf{D}, \mathbf{T} / \mathbf{D})$ & $\mathbf{1 . 2 - 1 . 5}$ & $\mathbf{1 . 2 - 1 . 8}$ & $\mathbf{1 . 2 - 2 . 1}$ \\
\hline 15 & 0.868 & 0.828 & 0.785 \\
\hline 30 & $\mathbf{0 . 7 2 1 , 4 0 . 3 9 \%}$ & $\mathbf{0 . 7 3 3 , 3 9 . 4 2 \%}$ & $\mathbf{0 . 7 4 3 , 3 8 . 5 9 \%}$ \\
\hline 45 & 0.759 & 0.782 & 0.801 \\
\hline 60 & 0.818 & 0.842 & 0.869 \\
\hline 90 & 0.938 & 0.946 & 0.953 \\
\hline
\end{tabular}


Tabel 5. Koefisien Hambat Pada $\mathrm{S} / \mathrm{D}=1.8$, Variasi T/D dan $\alpha$ Dengan Tiga Pasif Kontrol

\begin{tabular}{|c|c|c|c|}
\hline$\left.{ }^{\circ}, \mathbf{S} / \mathbf{D}, \mathbf{T} / \mathbf{D}\right)$ & $\mathbf{1 . 8}-\mathbf{1 . 5}$ & $\mathbf{1 . 8 - 1 . 8}$ & $\mathbf{1 . 8 - 2 . 1}$ \\
\hline 15 & 0.822 & 0.783 & 0.741 \\
\hline 30 & $\mathbf{0 . 6 9 0 , 4 2 . 9 8 \%}$ & $\mathbf{0 . 7 0 1 , 4 2 . 0 6 \%}$ & $\mathbf{0 . 7 1 0 , 4 1 . 2 9 \%}$ \\
\hline 45 & 0.728 & 0.742 & 0.758 \\
\hline 60 & 0.778 & 0.799 & 0.823 \\
\hline 90 & 0.896 & 0.902 & 0.908 \\
\hline
\end{tabular}

Tabel 6. Koefisien Hambat Pada S/D=2.4, Variasi T/D dan $\alpha$ Dengan Tiga Pasif Kontrol

\begin{tabular}{|c|c|c|c|}
\hline${ }^{\circ},(\mathbf{S} / \mathbf{D}, \mathbf{T} / \mathbf{D})$ & $\mathbf{2 . 4 - 1 . 5}$ & $\mathbf{2 . 4 - 1 . 8}$ & $\mathbf{2 . 4 - 2 . 1}$ \\
\hline 15 & 0.822 & 0.784 & 0.742 \\
\hline 30 & $\mathbf{0 . 6 9 2 , 4 2 . 8 1 \%}$ & $\mathbf{0 . 7 1 1 , 4 1 . 1 9 \%}$ & $\mathbf{0 . 7 1 1 , 4 1 . 1 9 \%}$ \\
\hline 45 & 0.727 & 0.756 & 0.756 \\
\hline 60 & 0.774 & 0.821 & 0.821 \\
\hline 90 & 0.775 & 0.905 & 0.905 \\
\hline
\end{tabular}

Tabel 7. Koefisien Hambat Pada S/D=3.0, Variasi T/D dan $\alpha$ Dengan Tiga Pasif Kontrol

\begin{tabular}{|c|c|c|c|}
\hline$\left.{ }^{\circ}, \mathbf{S} / \mathbf{D}, \mathbf{T} / \mathbf{D}\right)$ & $\mathbf{3 . 0 - 1 . 5}$ & $\mathbf{3 . 0 - 1 . 8}$ & $\mathbf{3 . 0 - 2 . 1}$ \\
\hline 15 & 0.840 & 0.803 & 0.760 \\
\hline 30 & $\mathbf{0 . 7 0 7 , 4 1 . 5 4 \%}$ & $\mathbf{0 . 7 1 7 , 4 0 . 7 4 \%}$ & $\mathbf{0 . 7 2 6 , 4 1 . 1 9 \%}$ \\
\hline 45 & 0.741 & 0.756 & 0.770 \\
\hline 60 & 0.787 & 0.811 & 0.835 \\
\hline 90 & 0.902 & 0.911 & 0.919 \\
\hline
\end{tabular}

Pada berbagai macam variasi rasio jarak T/D dan S/D, penurunan koefisien hambat yang bagus terjadi pada saat $\mathrm{T} / \mathrm{D}=1.5$ dan $\mathrm{S} / \mathrm{D}=1.8$. Kemudian, dengan memperhatikan besar sudut antara dua pasif kontrol di belakang silinder sirkular, $\alpha$ yang paling optimal untuk menurunkan koefisien hambat yaitu $\alpha=30^{\circ}$. Pada konfigurasi tersebut, koefisien hambat dapat turun hingga 42.98\%. Dengan memperhatikan jumlah pasif kontrol yang diletakkan di sekitar silinder, konfigurasi tiga pasif kontrol yang tepat adalah metode yang paling bagus untuk menurunkan koefisien hambat yang diterima silinder sirkular dibandingkan dengan pasif kontrol tunggal atau dua pasif kontrol.

\section{Simpulan}

Pasif kontrol di sekitar silinder sirkular yang dilalui aliran fluida dengan bilangan Reynolds 1000 mampu menurunkan koefisien hambat yang diterima silinder sirkular. Modifikasi bentuk, jumlah dan konfigurasi letak pasif kontrol mempengaruhi efektifitas penurunan koefisien 
hambat. Dengan konfigurasi tiga pasif kontrol yang tepat yaitu pasif kontrol pertama diletakkan di depan silinder sirkular pada rasio jarak $\mathrm{S} / \mathrm{D}=1.8$ dan dua pasif kontrol lainnya diletakkan di belakang silinder sirkular pada rasio jarak $\mathrm{T} / \mathrm{D}=1.5$ dengan $\alpha=30^{\circ}$ mampu menurunkan koefisien hambat yang paling optimal hingga mencapai $42.98 \%$.

\section{$5 \quad$ Ucapan Terima Kasih}

Ucapan Terima Kasih, kami sampaikan kepada LPPM ITS dan MenRisTekDikTi yang telah memberikan Dana Penelitian melalui PDUPT tahun kedua (2018).

\section{Daftar Pustaka}

[1] Ladjedel, A.O., Yahiaoui, B.T., Adjlout, C.L. and Imine, D.O., Experimental and numerical studies of drag reduction on a circular cylinder. World Academy of Science, Engineering and Technology, 77, pp.357-361, 2011.

[2] Igarashi, T. and Shiba, Y., Drag Reduction for D-Shape and I-Shape Cylinders. JSME International Journal Series B Fluids and Thermal Engineering, 49(4), pp.1036-1042, 2006.

[3] Yuwono, T. and Widodo, W.A., February. Flow characteristics around a D-type cylinder near a plane wall. In Proceedings of the Regional Conferences on Mechanical and Aerospace Technology, Bali, Indonesia., pp. 9-10, 2010.

[4] Bouak, F. \& Lemay, J., Passive Control of The Aerodynamic Forces Acting on a Circular Cylinder, Experimental Thermal and Fluid Science 16, 112-121, 1998.

[5] Lee, S. J., Lee, S. I., \& Park, C. W., Reducing the drag on a circular cylinder by upstream installation of a small control rod. Fluid dynamics research, 34(4), 233, 2004.

[6] Triyogi, Y., \& Nuh, M., Using of a Bluff Body Cut from a Circular Cylinder as passive Control to reduce Aerodynamics Forces on a Circular Cylinder. In The International Conference on Fluid and Thermal energy Conversion (pp. 7-11), 2003.

[7] Imron, C., Widodo, B., \& Yuwono, T., Numerical simulation of fluid flow around circular and I-shape cylinder in a tandem configuration. Applied Mathematical Sciences, 7(114), 5657-5666, 2013.

[8] Tsutsui, T. \& Igarashi, T. Drag Reduction of a Circular Sylinder in an Air-Stream, Journal of Wind Engineering and Industrial Aerodynamics 90, 527-541, 2002.

[9] Widodo, B., Yuwono, T. Y., \& Imron, C. The Influence of distance between passive control and circular cylinder on wake. In Journal of Physics: Conference Series (Vol. 890, 
No. 1, p. 012053). IOP Publishing, 2017.

[10] Hakam, A., Widodo, B., Yuwono, T. Y., \& Imron, C. Numerical investigation of the flow around circular cylinder with two passive controls. In Journal of Physics: Conference Series (Vol. 974, No. 1, p. 012011). IOP Publishing, 2018.

[11] A.L.F. Lima E. Silva, A. S.-N. \& Damasceno, J. Numerical Simulation of TwoDimensional Flows Over a Circular Cylinder Using the Immersed Boundary Method, Journal of Computational Physics 189, 351-370, 2003.

[12] Zulhidayat, D.N., M.-J. C. \& Horng, T.-L. An Immersed Boundary Method to Solve Fluid-Solid Interction Problems, Computational Mechanics 44, 447-453, 2009.

[13] Singha, S., \& Sinhamahapatra, K. P. Flow past a circular cylinder between parallel walls at low Reynolds numbers. Ocean Engineering, 37(8-9), 757-769, 2010.

[14] Matyka, M., Solution to two-dimensional incompressible Navier-Stokes equations with simple, simpler and vorticity-stream function approaches. driven-lid cavity problem: Solution and visualization. arXiv preprint physics/0407002, 2004. 